\title{
Uma Proposta de Instrumento para Avaliação da Educação a Distância
}

\author{
Cláudia M. Cruz Rodrigues* \\ José Luis Duarte Ribeiro** \\ Marcelo Cortimiglia*** \\ Cristiane Bündchen ${ }^{\star * \star *}$
}

\section{Resumo}

Este artigo propõe um instrumento de avaliação para a educação a distância, e relata a sua aplicação na Universidade Federal do Rio Grande do Sul. No desenvolvimento da proposta, foi realizada uma pesquisa bibliográfica e, posteriormente, uma pesquisa de campo a fim de testar o pré-instrumento de avaliação proposto junto aos alunos do Curso de Pedagogia a distância e a sua validação junto à amostra considerada. $\mathrm{O}$ instrumento proposto possui 67 itens que permitem avaliar as dimensões: (i) corpo docente, corpo de tutores e coordenação; (ii) organização didático-pedagógica e; (iii) instalações físicas. O alfa de Cronbach do instrumento foi de 0,982 , o que indica alta consistência interna, oportunizando a validação do instrumento. No total, 165 alunos participaram da pesquisa. Dada a generalidade do instrumento proposto, conclui-se que o mesmo pode ser aplicado para a avaliação da educação a distância ofertada por qualquer tipo de Instituição, seja de natureza pública ou privada.

Palavras-chave: Educação Superior. Educação a Distância. Instrumento de Avaliação.

\section{Introdução}

A Educação a Distância $(\mathrm{EaD})$ vem crescendo em ritmo acelerado em todas as áreas de conhecimento. Tal crescimento deve-se, em grande parte, à política adotada pelo Governo Federal em termos de estimular a oferta e proporcionar condições

* Doutora em Engenharia de Produção, Vice-Secretária de Avaliação Institucional da Universidade Federal do Rio Grande do Sul (UFRGS) e Professora do Departamento de Engenharia de Produção e Transportes. E-mail: claudia.rodrigues@producao.ufrgs.br.

** Doutor em Engenharia Civil, Professor e Chefe do Departamento de Engenharia de Produção e Transportes da Universidade Federal do Rio Grande do Sul (UFRGS). E-mail: ribeiro@producao.ufrgs.br.

*** Bolsista de Pós-doutorado CNPq junto ao Programa de Pós-Graduação em Engenharia de Produção (UFRGS). E-mail: cortimiglia@producao.ufrgs.br.

**** Bacharel em Estatística pela Universidade Federal do Rio Grande do Sul (UFRGS).

E-mail: crisbundchen@gmail.com. 
para que todos possuam acesso ao ensino superior. Desta forma, medidas como a reestruturação e revitalização do ensino foram adotadas e, com elas, estratégias para garantir que princípios como o da qualidade, respeito à identidade e à diversidade institucional, globalidade, legitimidade e permanência sejam adotados.

Neste sentido, os Referenciais de Qualidade para Educação a Distância, propostos pela Secretaria de Educação a Distância do Ministério da Educação (SEED/MEC), fornecem orientações que subsidiam a discussão dos Projetos Pedagógicos dos Cursos, orientando e fixando bases para que a busca da qualidade aconteça de forma contínua e permanente. Para tanto, os Referenciais propõem a observância dos seguintes critérios: (i) concepção de educação e currículo no processo de ensino e aprendizagem; (ii) sistemas de comunicação; (iii) material didático; (iv) avaliação; (v) equipe multidisciplinar; (vi) infraestrutura de apoio; (vii) gestão acadêmico-administrativa e, (viii) sustentabilidade financeira.

Este trabalho propõe explorar as temáticas da avaliação, abordando a avaliação da aprendizagem e a avaliação institucional. Enquanto tratando-se da avaliação da aprendizagem, segundo os Referenciais de Qualidade, o modelo a ser adotado pelas instituições deve ajudar o estudante a desenvolver graus mais complexos de competências cognitivas, habilidades e atitudes. Tal avaliação deve ocorrer de forma contínua, para verificar constantemente o progresso dos estudantes, e estimulá-los a serem ativos na construção do conhecimento, articulando mecanismos que promovam o permanente acompanhamento dos estudantes, no intuito de identificar eventuais dificuldades na aprendizagem, e saná-las ainda durante o processo de ensino-aprendizagem.

Quanto à avaliação institucional, os Referenciais orientam as instituições no sentido de planejamento e implementação de sistemas de avaliação institucional a fim de produzirem melhorias efetivas de qualidade nas condições de oferta dos cursos e no processo pedagógico. Para tanto, deve-se configurar em um processo permanente e consequente, de modo a subsidiar o aperfeiçoamento dos sistemas de gestão e pedagógico, produzindo, de maneira efetiva, correções na direção da melhoria da qualidade do processo pedagógico coerentemente com o Sistema Nacional de Avaliação da Educação Superior (SINAES). Para ter sucesso neste processo, as instituições devem planejar sistemas que contemplem a avaliação das dimensões: (1) corpo docente, corpo de tutores, corpo técnico-administrativo, e discentes; (2) organização didático-pedagógica; (3) instalações. A avaliação destas dimensões deve ser coerente com o proposto pelo SINAES. 
A Universidade Federal do Rio Grande do Sul (UFRGS) atualmente possui um instrumento para avaliação do processo ensino-aprendizagem. Tal instrumento é disponibilizado no portal do aluno ao final de cada semestre letivo tanto para o ensino presencial, quanto para o ensino a distância. Através de 25 questões, o instrumento avalia os seguintes critérios: (i) avaliação do professor; (ii) avaliação da disciplina; (iii) avaliação da infraestrutura e, (iv) autoavaliação do aluno. Verifica-se que esse instrumento não está adequado para avaliar a dinâmica dos cursos a distância da Universidade, tendo em vista a proposição de outros elementos, bem como: atuação de tutores presenciais e a distância, uso das ferramentas da tecnologia de informação e comunicação, e presença dos polos como local de funcionamento dos cursos oferecidos.

Neste contexto, é importante salientar as orientações gerais do Roteiro de AutoAvaliação Institucional do SINAES, em relação ao cumprimento por parte das instituições dos procedimentos de avaliação e acompanhamento do planejamento institucional, especialmente das atividades educativas mencionadas na dimensão 8, que trata do planejamento e da avaliação.

Dadas as particularidades dos cursos presenciais e a distância, verifica-se que, na realidade, os cursos $\mathrm{EaD}$ não utilizam o instrumento proposto pela Universidade citado anteriormente, e cada curso acaba desenvolvendo seus próprios instrumentos e/ou meios de avaliação para ter um mapeamento geral da sua situação. Tal situação traz algumas dificuldades, pois os instrumentos utilizados são incompletos, e é moroso comparar resultados dos diferentes cursos. Além disso, outro agravante é o fato de que a avaliação discente é exigida para fins de progressão docente de acordo com a legislação vigente da Universidade.

Este estudo objetiva propor um instrumento de avaliação da educação a distância para Instituições de Educação Superior, sejam Universidades, Centros Universitários, Faculdades e Institutos Especializados, de natureza pública ou privada.

Para tanto, a seção 2 trata do referencial teórico sobre o tema em questão, a seção 3 apresenta os procedimentos metodológicos adotados, a seção 4, os resultados e, por fim, a seção 5 apresenta as considerações finais do presente estudo. 


\section{Referencial Teórico}

\subsection{Panorama do Ensino Superior}

O Censo da Educação Superior de 2009 registrou a participação de 2.314 Instituições de Ensino Superior (IES) no País; 28.966 Cursos, sendo 28.771 de graduação e 295 sequenciais de formação específica; 5.954.021 matrículas, e dessas, 838.125 no ensino a distância, destacando-se a predominância do setor privado com 665.429 matrículas (79,4\% na EaD). Em 2001, havia 5.359 matrículas na educação à distância, um aumento de 64\% em relação ao ano de 2009.

Ao comparar a distribuição do número de matrículas por grau acadêmico, segundo a modalidade de ensino, verifica-se que, enquanto $71 \%$ dos cursos presenciais são de bacharelado, metade dos cursos EaD é de licenciatura (CENSO, 2009). A Figura 1 apresenta os dez maiores cursos de graduação, de uma forma geral, assim como os dez maiores cursos no ensino presencial e no ensino a distância, demonstrando que os cursos de Pedagogia e Administração detêm $61,5 \%$ das matrículas na educação a distância.

Figura 1 - Os dez maiores cursos de graduação do Brasil, em número de matrículas, por modalidade de ensino

\begin{tabular}{|c|c|c|c|c|c|c|c|c|}
\hline \multicolumn{3}{|c|}{ Presencial } & \multicolumn{3}{|c|}{ Educação a Distância } & \multicolumn{3}{|c|}{ Geral } \\
\hline Curso & Matrículas & $\%$ & Curso & Matrículas & $\%$ & Curso & Matrículas & $\%$ \\
\hline $\begin{array}{l}\text { Adminis- } \\
\text { tração }\end{array}$ & 874.076 & 17,1 & $\begin{array}{l}\text { Pedago- } \\
\text { gia }\end{array}$ & 286.771 & 34,2 & $\begin{array}{l}\text { Adminis- } \\
\text { tração }\end{array}$ & 1.102 .579 & 18,5 \\
\hline Direito & 651.600 & 12,7 & $\begin{array}{l}\text { Adminis- } \\
\text { tração }\end{array}$ & 228.503 & 27,3 & Direito & 651.730 & 10,9 \\
\hline $\begin{array}{l}\text { Engenha- } \\
\text { ria }\end{array}$ & 419.397 & 8,2 & \begin{tabular}{|l} 
Serviço \\
social e \\
orienta- \\
ção
\end{tabular} & 68.055 & 8,1 & $\begin{array}{l}\text { Pedago- } \\
\text { gia }\end{array}$ & 573.898 & 9,6 \\
\hline $\begin{array}{l}\text { Pedago- } \\
\text { gia }\end{array}$ & 287.127 & 5,6 & Letras & 49.749 & 5,9 & $\begin{array}{l}\text { Engenha- } \\
\text { ria }\end{array}$ & 420.578 & 7,1 \\
\hline $\begin{array}{l}\text { Enferma- } \\
\text { gem }\end{array}$ & 235.281 & 4,6 & $\begin{array}{l}\text { Ciências } \\
\text { contábeis }\end{array}$ & 29.944 & 3,6 & $\begin{array}{l}\text { Enferma- } \\
\text { gem }\end{array}$ & 235.804 & 4 \\
\hline $\begin{array}{l}\text { Comu- } \\
\text { nicação } \\
\text { Social }\end{array}$ & 205.409 & 4 & $\begin{array}{l}\text { Matemá- } \\
\text { tica }\end{array}$ & 23.774 & 2,8 & $\begin{array}{l}\text { Ciências } \\
\text { Contá- } \\
\text { beis }\end{array}$ & 235.274 & 4 \\
\hline
\end{tabular}

(Continua) 


\begin{tabular}{|l|c|c|l|c|c|l|c|c|}
\hline $\begin{array}{l}\text { Ciências } \\
\text { Contá- } \\
\text { beis }\end{array}$ & 205.330 & 4 & $\begin{array}{l}\text { Ciências } \\
\text { biológi- } \\
\text { cas }\end{array}$ & 19.626 & 2,3 & $\begin{array}{l}\text { Comu- } \\
\text { nicação } \\
\text { Social }\end{array}$ & 221.211 & 3,7 \\
\hline $\begin{array}{l}\text { Educação } \\
\text { Física }\end{array}$ & 163.528 & 3,2 & História & 16.864 & 2 & Letras & 194.990 & 3,3 \\
\hline Letras & 145.241 & 2,8 & $\begin{array}{l}\text { Comu- } \\
\text { nicação } \\
\text { social }\end{array}$ & 15.802 & 1,9 & $\begin{array}{l}\text { Educação } \\
\text { Física }\end{array}$ & 165.848 & 2,8 \\
\hline $\begin{array}{l}\text { Ciências } \\
\text { Biológi- } \\
\text { cas }\end{array}$ & 133.204 & 2,6 & $\begin{array}{l}\text { Ciências } \\
\text { tambien- } \\
\text { tais e } \\
\text { proteção } \\
\text { ambien- } \\
\text { tal }\end{array}$ & 13.091 & 1,6 & $\begin{array}{l}\text { Ciências } \\
\text { Biológi- } \\
\text { cas }\end{array}$ & 152.830 & 2,6 \\
\hline $\begin{array}{l}\text { Outros } \\
\text { Cursos }\end{array}$ & 1.795 .703 & 35,1 & $\begin{array}{l}\text { Outros } \\
\text { Cursos }\end{array}$ & 85.946 & 10, & $\begin{array}{l}\text { Outros } \\
\text { Cursos }\end{array}$ & 1.999 .279 & 33,6 \\
\hline Total & $\mathbf{5 . 1 1 5 . 8 9 6}$ & $\mathbf{1 0 0}$ & \begin{tabular}{l} 
Total \\
\hline
\end{tabular}
\end{tabular}

Fonte: MINISTÉRIO DA EDUCAÇÃO, 2009.

Importante informação no que tange a EaD refere-se ao perfil do aluno. De acordo com o Censo 2009, o aluno EaD ingressa mais tardiamente do que o aluno da graduação presencial e, por consequência, a conclusão do curso ocorre em média aos 36 anos, enquanto no ensino presencial, os alunos concluem aos 28 anos. Em relação ao sexo, na graduação presencial, as mulheres correspondem a 55,1\% do número de matrículas e a 58,8\% do número de concluintes. Já na modalidade de $\mathrm{EaD}, 69,2 \%$ das matrículas e $76,2 \%$ dos concluintes são do sexo feminino.

\subsection{A Educação a Distância}

No entender de Aretio (1991), docente da Universidade Nacional de Educação a Distância da Espanha (UNED), a educação a distância é uma expressão imprecisa a qual se pode atribuir diversos sentidos. O Quadro 1 apresenta, na opinião de Aretio (1991), as diversas concepções de autores reconhecidos que tem participado ativamente no desenvolvimento da educação a distância. 
Quadro 1 - Concepções de educação a distância

\begin{tabular}{|c|c|}
\hline Autor & Educação a Distância \\
\hline $\begin{array}{l}\text { Michael Moore } \\
\text { (1972) }\end{array}$ & $\begin{array}{l}\text { É um tipo de método de instrução em que as condutas docentes } \\
\text { acontecem a parte das discentes, de tal maneira que a comunica- } \\
\text { ção entre o professor e o aluno possa realizar-se mediante textos } \\
\text { impressos, por meios eletrônicos, mecânicos ou outras maneiras. }\end{array}$ \\
\hline $\begin{array}{l}\text { Börje Hölmberg } \\
\text { (1977) }\end{array}$ & $\begin{array}{l}\text { O termo cobre distintas formas de estudo em todos os níveis, su- } \\
\text { pervisão imediata dos tutores presenciais com os estudos em aula, } \\
\text { no entanto, se beneficiam do planejamento, guia e sequência de } \\
\text { uma organização tutorial. }\end{array}$ \\
\hline R. S. Sims (1977) & $\begin{array}{l}\text { No transcurso do processo ensino-aprendizagem, o aluno se } \\
\text { encontra a certa distância do professor, seja durante uma parte ou } \\
\text { maior parte, ou durante todo o tempo do processo. }\end{array}$ \\
\hline A.Kaye (1979) & $\begin{array}{l}\text { Pode-se atender, em geral, a uma população estudantil dispersa } \\
\text { geograficamente e, em particular, aquelas que se encontram em } \\
\text { zonas periféricas e que não dispõem das redes das instituições } \\
\text { convencionais; favorece a possibilidade de personalizar o proces- } \\
\text { so de aprendizagem para garantir uma sequência acadêmica que } \\
\text { responde ao ritmo do rendimento do estudante. }\end{array}$ \\
\hline $\begin{array}{l}\text { Norman McKenzie } \\
\text { y otros (1979) }\end{array}$ & $\begin{array}{l}\text { O sistema deve facilitar a participação de todos que querem apren- } \\
\text { der, sem impor-lhes os requisitos tradicionais de ingresso, mas a } \\
\text { obtenção de um título acadêmico, ou qualquer outro certificado, } \\
\text { seja a única recompensa. }\end{array}$ \\
\hline $\begin{array}{l}\text { Jaime Sarramona } \\
\text { (1979) }\end{array}$ & $\begin{array}{l}\text { É um sistema didático em que as condutas docentes têm lugar a } \\
\text { parte das condutas discentes de modo que a comunicação profes- } \\
\text { sor-aluno fique diferenciada no tempo, no espaço ou em ambos. }\end{array}$ \\
\hline $\begin{array}{l}\text { Desmond Keegan } \\
\text { (1980) }\end{array}$ & $\begin{array}{l}\text { A separação entre o professor e aluno que a distingue das classes } \\
\text { cara a cara; a influência de uma organização educacional que a } \\
\text { distingue do estudo privado; }\end{array}$ \\
\hline $\begin{array}{l}\text { Pio Navarro Alcalá } \\
\text { Zamora (1981) }\end{array}$ & $\begin{array}{l}\text { São aquelas formas de estudo que não são guiadas e/ou controla- } \\
\text { das diretamente pela presença do professor em aula, ainda que se } \\
\text { beneficiem do planejamento, guia e ensino de professores-tutores, } \\
\text { através de algum meio de comunicação social que permita a intera- } \\
\text { ção professor-aluno, sendo este o responsável exclusivo pelo ritmo } \\
\text { e realização de seus estudos. }\end{array}$ \\
\hline $\begin{array}{l}\text { Miguel Casas Ar- } \\
\text { mengol (1982) }\end{array}$ & $\begin{array}{l}\text { O termo cobre uma ampla gama de diversas formas de estudos e } \\
\text { estratégias educativas, que tem em comum o fato de não cumpri- } \\
\text { rem-se mediante a tradicional continuidade física de professores e } \\
\text { alunos em locais especiais para fins educativos. }\end{array}$ \\
\hline $\begin{array}{l}\text { Hilary Perraton } \\
\text { (1982) }\end{array}$ & $\begin{array}{l}\text { É um processo educativo em que uma parte considerável do ensino } \\
\text { é dirigida por alguém afastado no espaço e/ou no tempo. }\end{array}$ \\
\hline $\begin{array}{l}\text { Gustavo Cirigliano } \\
\text { (1983) }\end{array}$ & $\begin{array}{l}\text { É o ponto intermediário de uma linha contínua em cujos extremos } \\
\text { se situam, por uma parte, a relação presencial professor-aluno e, } \\
\text { por outra, a educação autodidata, aberta, em que ao aluno não } \\
\text { necessita da ajuda do professor. }\end{array}$ \\
\hline
\end{tabular}




\begin{tabular}{|c|c|}
\hline Otto Peters (1983) & $\begin{array}{l}\text { O ensino/ educação a distância é um método de compartilhar } \\
\text { conhecimentos, habilidades e atitudes, racionalizando mediante a } \\
\text { aplicação da divisão do trabalho e de princípios organizativos. }\end{array}$ \\
\hline $\begin{array}{l}\text { Victor Guédez } \\
\text { (1984) }\end{array}$ & $\begin{array}{l}\text { É uma modalidade mediante a qual se transferem informações cogni- } \\
\text { tivas e mensagens formativas através de vias que não requerem uma } \\
\text { relação de continuidade presencial em ambientes determinados. }\end{array}$ \\
\hline $\begin{array}{l}\text { Ricardo Marín } \\
\text { Ibánez (1984) }\end{array}$ & $\begin{array}{l}\text { Definir ensino a distância visto que não é imprescindível que o pro- } \\
\text { fessor esteja junto ao aluno não é de todo exato, a parte de ser um } \\
\text { grande desvio meramente negativo. No ensino a distância, a relação } \\
\text { didática tem um caráter múltiplo. Há que percorrer uma pluralidade } \\
\text { de vias. É um sistema multimídia. }\end{array}$ \\
\hline $\begin{array}{l}\text { Miguel A. Ramón } \\
\text { Martinez (1985) }\end{array}$ & $\begin{array}{l}\text { É uma estratégia para operacionalizar os princípios e os fins da edu- } \\
\text { cação permanente e aberta, de tal maneira que qualquer pessoa, } \\
\text { independente do tempo e do espaço, possa converter-se em sujeito } \\
\text { protagonista de sua própria aprendizagem graças ao uso sistemá- } \\
\text { tico de materiais educativos, reforçados com diferentes meios e } \\
\text { formas de comunicação. }\end{array}$ \\
\hline $\begin{array}{l}\text { José Luis García } \\
\text { Llamas (1986) }\end{array}$ & $\begin{array}{l}\text { É uma estratégia educativa baseada na aplicação da tecnologia à } \\
\text { aprendizagem sem limitação de lugar, tempo, ocupação ou idade } \\
\text { dos estudantes, implica novos papéis para os alunos e para os pro- } \\
\text { fessores e novas atitudes e novos enfoques metodológicos. }\end{array}$ \\
\hline Doina Popa (1986) & $\begin{array}{l}\text { Educação a distância, que deixa de ser um obstáculo para conver- } \\
\text { ter-se em um aliado; seu caráter inovador, não tradicional; o uso de } \\
\text { nova tecnologia na educação; o novo enfoque da atividade educa- } \\
\text { tiva, centrada principalmente na atividade discente, aprendizagem } \\
\text { individual que possa perfeitamente desenvolver-se fora das aulas, } \\
\text { no mesmo lugar, etc. }\end{array}$ \\
\hline $\begin{array}{l}\text { Derek Rowntree } \\
\text { (1986) }\end{array}$ & $\begin{array}{l}\text { Aquele sistema de ensino em que o estudante realiza a maior parte } \\
\text { de sua aprendizagem por meio de materiais didáticos previamente } \\
\text { preparados, com o escasso contato direto com os professores. As- } \\
\text { sim mesmo, pode ter o contato ocasional com outros estudantes. }\end{array}$ \\
\hline Aretio (1991) & $\begin{array}{l}\text { É um sistema tecnológico de comunicação massiva e bidirecional, } \\
\text { que substitui a interação pessoal em aula de professor e aluno } \\
\text { como meio preferencial de ensino pela ação sistemática e conjunta } \\
\text { de diversos recursos didáticos e de apoio de uma organização tuto- } \\
\text { rial, que propicia a aprendizagem autônoma dos estudantes. }\end{array}$ \\
\hline
\end{tabular}

Fonte: Aretio (1991, p. 7).

No entender de Faller (2009), o ambiente da educação a distância integra elementos/dimensões que interagem entre si no processo de ensino-aprendizagem utilizando-se: (1) das tecnologias, como chats, fóruns, e-mails, CDs, DVDs, etc.; (2) da estrutura dos polos (espaço físico, bibliotecas, laboratórios, etc.), assim como do Projeto Pedagógico do Curso (PPC); (3) das pessoas que oportunizam que o PPC seja colocado em prática, ou seja, professores, coordenadores de polos e do curso, tutores, orientadores e funcionários, conforme explicita a Figura 2. 
Figura 2- Ambiente da educação a distância

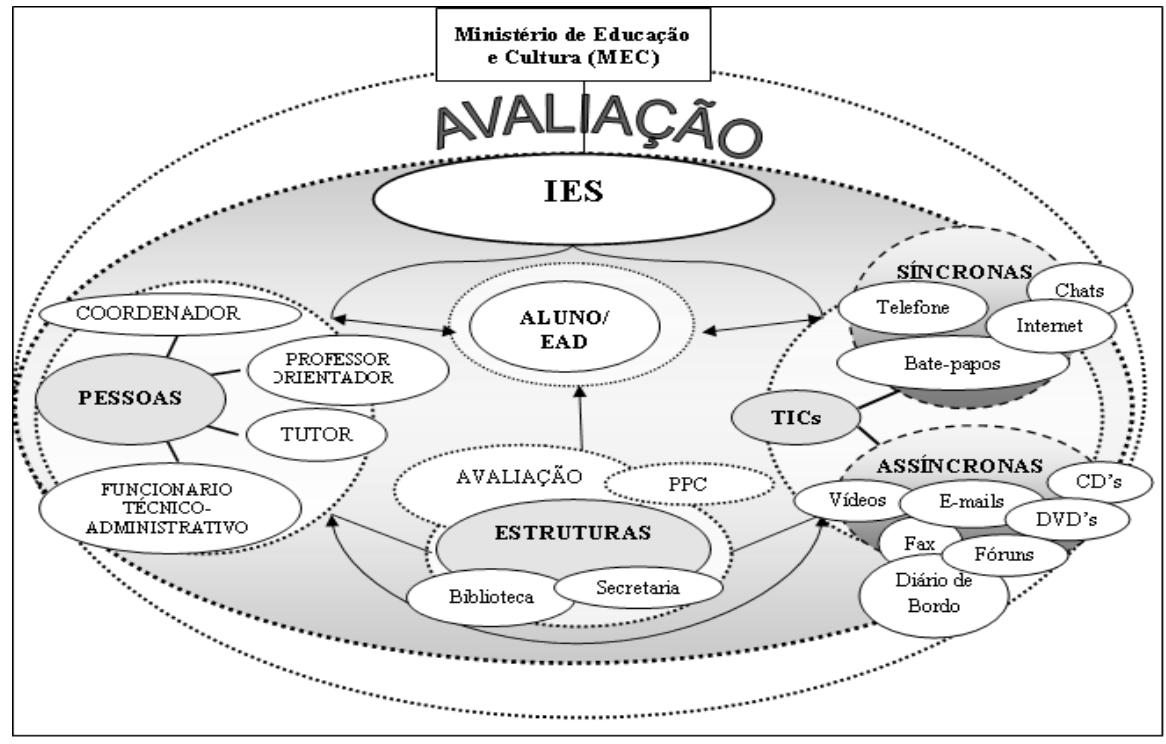

Fonte: Faller (2009).

Tratando-se da avaliação na educação a distância, a mesma acontece em dois momentos distintos: (1) vinculando-se à estrutura de apoio fornecida pelo polo, sendo processual ou formativa, e/ou final ou somativa; (2) envolvendo as três dimensões do desenho de pesquisa, tratando-se de uma avaliação de maior abrangência (FALLER, 2009).

No entender de Leite (2005), o processo avaliativo não pode ser uma fôrma, um modelo que oferece um padrão único e técnico para analisar situações que são humanas e complexas. Assim, é importante conhecer as formas como as avaliações se apresentam, o que permite compreender e escolher os alcances confiáveis, técnicos e políticos, para desvendar as possíveis verdades sobre uma situação. É importante entender as racionalidades presentes nos diferentes formatos de avaliação, sejam educacionais ou institucionais, distinguindo seus efeitos e implicações.

Nas aulas, presenciais e não presenciais, os procedimentos costumam ser ritualizados e reprodutivistas, produzidos por um dispositivo pedagógico e um discurso pedagógico que regula a ordem. Desta forma, as práticas educativas podem reproduzir modos de subjetivação individualista e possessivo através da avaliação. (...) Por outro lado, em situações de ensino com as TICs a avaliação tem mos- 
trado ser um processo de aprendizado colaborativo (Seria também participativo?) quando em situação de intercâmbio do saber-fluxo (LÉVY, 1998), não necessariamente do saber - institucionalizado e formal. Nesse aspecto, a aprendizagem pode atingir um grau de autonomia do sujeito frente ao saber auto-gerido que comporta o seu contrário, ou seja, o fechamento de sentidos para o coletivo. Nessas oposições, características do momento vivido em educação, situam-se as justificativas para aumentar a compreensão sobre avaliações que envolvam participação (LEITE et al., 2007, p. 447).

Leite et al. (2007) comenta sobre a necessidade do entendimento da dinâmica da sala de aula, tendo em vista a sociedade da informação e da comunicação, na qual o papel do professor e do aluno na aprendizagem com o auxílio das máquinas está em constante mudança: "[...] O docente aprende junto com os alunos, ambos como profissionais aprenderão de forma continuada, por toda vida, online e off-line"; [...] O que muda são os paradigmas das práticas pedagógicas, as identidades e mentalidades, os modos de subjetivação dos aprendizes, a forma de transação com o conhecimento"; [...] (LEITE et al., 2007, p. 447).

Neste contexto, é importante salientar o papel do Ministério da Educação na avaliação de instituições, cursos e estudantes. O sentido da avaliação nos moldes 'ora impostos' traz consigo uma gama de indicadores de qualidade que devem ser observados e cumpridos pelas instituições. A avaliação, no contexto do SINAES, está totalmente à mercê da regulação, sendo, inclusive, afetada pela natureza das informações prestadas nos sistemas computacionais por parte das instituições.

Ao compreender o cenário vivenciado pelas instituições que promovem a educação a distância, a literatura disponível em relação ao assunto, como a visão da participação mencionada anteriormente por Leite et al. (2007), e os sujeitos que fazem parte do processo mencionado por Faller (2009), percebe-se a necessidade de instrumentos capazes de auxiliar o mapeamento das potencialidades e fragilidades relacionadas ao estudante, ao curso e à instituição como um todo.

Os instrumentos, ora disponíveis pelo Ministério da Educação, para avaliar a educação a distância (autorização e reconhecimento de cursos, credenciamento de polos e credenciamento institucional) trazem consigo parcela desta informação, deixando a critério de cada instituição de ensino, a proposição de ferramentas que venham, de fato, a avaliar os diversos elementos que constituem o ambiente da educação a distância. 
Neste sentido, os estudos de Faller (2009), Rodrigues, Oliveira e Rodrigues et al. (2009), Faller e Rodrigues (2010), sinalizam importantes contribuições no que tange a proposição de indicadores para avaliação de cursos de graduação e pós-graduação na modalidade a distância, assim como algumas propostas já aplicadas em outros contextos.

\section{Procedimentos Metodológicos}

Este trabalho caracteriza-se como um estudo de caso que, na concepção de Yin (2007, p. 32), "é uma investigação empírica que investiga um fenômeno contemporâneo dentro de seu contexto da vida real, especialmente quando os limites entre o fenômeno e o contexto não estão claramente definidos". O estudo de caso foi realizado na UFRGS e teve como objeto de pesquisa a educação a distância.

A UFRGS oferece, atualmente, sete cursos de graduação a distância, todos dentro dos programas de fomento dessa modalidade do Ministério da Educação, disponibilizados como Programas Especiais de Graduação, de acordo com a Resolução CEPE n 37/2006 (UNIVERSIDADE FEDERAL DO RIO GRANDE DO SUL, 2009). Foi selecionado para ser objeto de investigação, o curso de Licenciatura em Pedagogia por ser o primeiro curso a distância da Universidade em processo de diplomação e, de acordo com os dados apresentados no Censo 2009, o curso com o maior número de matrículas na educação a distância no país, conforme evidenciado na Figura 1.

A coleta de dados foi efetuada em três etapas. Na primeira etapa, foi realizada pesquisa bibliográfica a partir dos instrumentos e da legislação relacionada à educação a distância disponibilizada pelo Ministério da Educação, assim como da literatura disponível sobre o tema. Esta etapa permitiu a construção da versão preliminar do instrumento de avaliação. Na segunda etapa, foi realizada uma pesquisa de campo para aplicação de um pré-teste do instrumento de avaliação junto aos alunos do Curso de Licencitura em Pedagogia a distância, que é ofertado para funcionamento em cinco polos: Alvorada, Gravataí, São Leopoldo, Sapiranga e Três Cachoeiras. A última etapa consistiu-se na consolidação do instrumento, através de sua validação junto à amostra considerada (Apêndice A).

Cabe salientar que a escala adotada no instrumento de coleta é de concordância, onde o 1 refere-se a Discordo Plenamente e 5 a Concordo Plenamente. O 
instrumento possui 67 itens que avaliam o grau de concordância geral do aluno em relação às seguintes dimensões e constructos:

(1). Corpo docente, corpo de tutores e coordenação: compreende Professores, Tutores Presenciais, Tutores a Distância e Coordenação de Curso e Polo;

(2). Organização didático-pedagógica: compreende Sistema de Ensino, Participação em Atividades Acadêmicas, Organização do Curso e Expectativas referentes a Conhecimento e Empregabilidade;

(3). Instalações físicas: compreende Condições do Polo, Suporte Acadêmico/ Técnico e Tecnologias de Informação e Comunicação (TIC).

\section{Resultados}

A pesquisa foi realizada nos meses de outubro a dezembro de 2010 junto ao Curso de Licenciatura em Pedagogia, modalidade a distância. Ao total, 165 alunos responderam ao instrumento implantado e disponibilizado via plataforma de aprendizagem utilizada pelo Curso. A seguir apresentam-se os resultados.

\subsection{Descrição da Amostra}

A população do estudo é formada pelos alunos matriculados no Curso de Pedagogia, na modalidade a distância da UFRGS, distribuída entre os polos de Alvorada (1), Gravataí (2), São Leopoldo (3), Sapiranga (4) e Três Cachoeiras (5). Da população de 347 alunos que se formaram nos cinco polos do Curso, 47,55\% responderam ao questionário, totalizando uma amostra de 165 respondentes. Dessa forma, o presente estudo tem sua amostra devidamente distribuída entre os cinco polos, conforme apresentado na Tabela 1.

Tabela 1 - Distribuição da população e dos entrevistados segundo os polos

\begin{tabular}{l|lllll}
\hline Pólo & $\begin{array}{l}\text { Alunos In- } \\
\text { gressantes }\end{array}$ & $\begin{array}{l}\text { Alunos } \\
\text { Formados }\end{array}$ & $\begin{array}{l}\text { Alunos En- } \\
\text { trevistados }\end{array}$ & $\begin{array}{l}\text { \% Entrevista- } \\
\text { dos/ Formados }\end{array}$ & $\begin{array}{l}\% \\
\text { Amostra }\end{array}$ \\
\hline Alvorada & 80 & 71 & 44 & 61,97 & 26,7 \\
Gravataí & 80 & 69 & 32 & 46,64 & 19,4 \\
São Leopoldo & 80 & 68 & 21 & 30,88 & 12,7 \\
Sapiranga & 80 & 68 & 36 & 52,94 & 21,8 \\
Três Cacho- & 80 & 71 & 32 & 45,07 & 19,4 \\
eiras & 400 & 347 & 165 & 47,55 & 100,0 \\
\hline Total & & & & &
\end{tabular}

Fonte: os autores (2014). 


\subsection{Descrição do Perfil dos Entrevistados}

A Tabela 2 apresenta a descrição do perfil dos entrevistados. Do total dos alunos respondentes, $98,8 \%$ são do sexo feminino; $35,8 \%$ têm dois filhos; $69,7 \%$ são casados; $62,4 \%$ trabalham como funcionário(a) do Governo Federal, Estadual Ou Municipal e 44,8\% possuem uma renda familiar de $\mathrm{R} \$ 1.020,00$ a $\mathrm{R} \$ 2.040,00$ (entre 2 e 4 salários mínimos).

Tabela 2 - Descrição geral da amostra, distribuição \% das diferentes categorias

\begin{tabular}{|c|c|c|c|c|c|c|}
\hline Variáveis & $\begin{array}{l}\text { Polo } \\
1\end{array}$ & $\begin{array}{l}\text { Polo } \\
2 \\
\end{array}$ & $\begin{array}{l}\text { Polo } \\
3 \\
\end{array}$ & $\begin{array}{l}\text { Polo } \\
4 \\
\end{array}$ & $\begin{array}{l}\text { Polo } \\
5 \\
\end{array}$ & $\begin{array}{l}\text { \% Total Entre- } \\
\text { vistados }\end{array}$ \\
\hline \multicolumn{7}{|l|}{ Sexo } \\
\hline Feminino & 97,7 & 96,9 & 100,0 & 100,0 & 100,0 & 98,8 \\
\hline Masculino & 2,3 & 3,1 & 0,0 & 0,0 & 0,0 & 1,2 \\
\hline \multicolumn{7}{|l|}{ Número de filhos } \\
\hline Nenhum & 11,4 & 9,4 & 4,8 & 22,2 & 37,5 & 17,6 \\
\hline Um & 34,1 & 43,8 & 23,8 & 30,6 & 21,9 & 31,5 \\
\hline Dois & 36,4 & 28,1 & 47,6 & 44,4 & 25,0 & 35,8 \\
\hline Três & 15,9 & 12,5 & 23,8 & 2,8 & 9,4 & 12,1 \\
\hline Quatro ou mais & 2,3 & 6,3 & 0,0 & 0,0 & 3,1 & 2,4 \\
\hline Não respondeu & 0,0 & 0,0 & 0,0 & 0,0 & 3,1 & 0,6 \\
\hline \multicolumn{7}{|l|}{ Estado Civil } \\
\hline Casado & 61,4 & 75,0 & 81,0 & 69,4 & 68,8 & 69,7 \\
\hline Solteiro & 13,6 & 9,4 & 4,8 & 16,7 & 21,9 & 13,9 \\
\hline Separado & 11,4 & 6,3 & 14,3 & 8,3 & 0,0 & 7,9 \\
\hline Viúvo & 2,3 & 0,0 & 0,0 & 0,0 & 3,1 & 1,2 \\
\hline Outro & 11,4 & 9,4 & 0,0 & 5,6 & 6,3 & 7,3 \\
\hline \multicolumn{7}{|l|}{ Ocupação } \\
\hline $\begin{array}{l}\text { No comércio, banco, trans- } \\
\text { porte, hotelaria ou outros } \\
\text { serviços }\end{array}$ & 0,0 & 0,0 & 0,0 & 0,0 & 18,8 & 3,6 \\
\hline $\begin{array}{l}\text { Como Funcionário (a) do } \\
\text { Governo Federal, Estadual } \\
\text { ou Municipal }\end{array}$ & 72,7 & 62,5 & 47,6 & 75,0 & 43,8 & 62,4 \\
\hline $\begin{array}{l}\text { Como profissional liberal, } \\
\text { professor (a) ou técnico (a) } \\
\text { de nível superior }\end{array}$ & 27,3 & 34,4 & 52,4 & 25,0 & 21,9 & 30,3 \\
\hline Não trabalha & 0,0 & 0,0 & 0,0 & 0,0 & 3,1 & 0,6 \\
\hline Outro & 0,0 & 3,1 & 0,0 & 0,0 & 12,5 & 3,0 \\
\hline
\end{tabular}

(Continua) 


\begin{tabular}{|c|c|c|c|c|c|c|}
\hline \multicolumn{7}{|l|}{ Renda } \\
\hline $\begin{array}{l}\text { De } R \$ 0 \text { a } R \$ 1020,00 \text { (até } 2 \\
\text { S.M.) }\end{array}$ & 18,2 & 9,4 & 9,5 & 16,7 & 25,0 & 16,4 \\
\hline $\begin{array}{l}\text { De } R \$ 1020,00 \text { a R } \$ 2040,00 \\
\text { (entre } 2 \text { e } 4 \text { S.M.) }\end{array}$ & 47,7 & 50,0 & 23,8 & 50,0 & 43,8 & 44,8 \\
\hline $\begin{array}{l}\text { De } R \$ 2040,00 \text { a } R \$ 5100,00 \\
\text { (entre } 4 \text { e } 10 \text { S.M.) }\end{array}$ & 29,5 & 40,6 & 57,1 & 33,3 & 31,3 & 36,4 \\
\hline $\begin{array}{l}\text { De } R \$ 5100,00 \text { a } R \$ 10200,00 \\
\text { (entre } 10 \text { e } 20 \text { S.M.) }\end{array}$ & 4,5 & 0,0 & 9,5 & 0,0 & 0,0 & 2,4 \\
\hline
\end{tabular}

Fonte: os autores (2014).

\subsection{Análise da Consistência Interna}

Foram realizados testes Alfa de Cronbach para a etapa de validação dos fatores, analisando o grau de consistência das variáveis e confiabilidade dos constructos, para os quais foi considerado o critério de $A l f a$ superior a 0,7 , obtendo-se valores superiores a $0,758 \mathrm{em}$ todos os constructos, o que corroborou a confiabilidade dos mesmos. As variáveis correspondentes a cada constructo, bem como os respectivos valores de Alfa, encontram-se discriminados na Tabela 3. Na concepção de Hair et al. (2005), um valor de pelo menos 0,70 aponta uma fidedignidade aceitável, mesmo reconhecendo que esse valor não seja um padrão absoluto.

Tabela 3 - Alfas de cronbach dos constructos

\begin{tabular}{c|c|c}
\hline Constructos & Variáveis & Alfa \\
\hline Professores & $01,02,03,04,05,06,07,08,09$ & 0,982 \\
\hline Tutores Presenciais & $10,11,12,13,14,15,16,17$ & 0,965 \\
\hline Tutores a Distância & $18,19,20,21,22,23,24,25,26$ & 0,971 \\
\hline Coordenação de Curso e Polo & $27,28,29$ & 0,915 \\
\hline Sistema de Ensino & $30,31,32,33,34,35$ & 0,903 \\
\hline Participação em Atividades Acadêmicas & $36,37,38,39,40$ & 0,897 \\
\hline Organização do Curso & $40,41,42,43,44$ & 0,884 \\
\hline Expectativas referentes a Conhecimento e Em- \\
pregabilidade & $45,46,47,48,49,50$ & 0,971 \\
\hline Condiçães do Polo & $51,52,53,54,55,56,57,58,59$ & 0,883 \\
\hline Suporte Acadêmico/Técnico & $60,61,62,63$ & 0,758 \\
\hline Tecnologias de Informação e Comunicação (TIC's) & $64,65,66,67$ & 0,806 \\
\hline
\end{tabular}

Observada a confiabilidade do constructo, este foi obtido a partir da média das variáveis que 0 compõem. Por exemplo, o constructo Professores refere-se à média das variáveis $01,02,03,04,05$, 06, 07, 08 e 09, cujo Alfa resultou em 0,982, e assim sucessivamente com as demais dimensões.

Fonte: os autores (2014). 


\subsection{Análise Descritiva e Comparativa das Dimensões}

Conforme os dados apresentados na Tabela 4, é possível constatar que o Polo de Três Cachoeiras obteve a menor média para os constructos Professores $(4,21)$, Tutores Presenciais (3,93), Participação em Atividades Acadêmicas $(3,91)$, Expectativas referentes a Conhecimento e Empregabilidade $(4,66)$ e Suporte Acadêmico/Técnico $(4,07)$.

O Polo de Gravataí obteve as maiores médias para os constructos Professores $(4,82)$, Tutores Presenciais $(4,75)$, Tutores a Distância $(4,87)$, Sistema de Ensino $(4,85)$, Participação em Atividades Acadêmicas $(4,68)$, Organização do Curso $(4,93)$, Suporte Acadêmico/Técnico $(4,41)$ e TIC's $(4,89)$, e obteve a menor média para o constructo Condições do Polo $(4,04)$.

Ainda, de acordo com a Tabela 4, quanto ao constructo Tutores a Distância, o Polo de São Leopoldo apresentou a menor média $(4,32)$, assim como para Sistema de Ensino (4,32), Organização do Curso (4,31) e TIC's (4,37).

O Polo de Sapiranga apresenta maiores médias para Expectativas referentes a Conhecimento e Empregabilidade $(4,92)$ e Condições do Polo $(4,45)$, entretanto, apresenta menor média para a Coordenação do Curso e Polo $(4,14)$.

Tabela 4 - Diferença de média dos constructos, por polo e total

\begin{tabular}{c|c|c|c|c|c|c}
\hline \multirow{2}{*}{ Constructo } & $\begin{array}{c}\text { Polo 1 } \\
\text { Alvo- } \\
\text { rada }\end{array}$ & $\begin{array}{c}\text { Polo 2 } \\
\text { Grava- } \\
\text { taí }\end{array}$ & $\begin{array}{c}\text { Polo } \\
\text { 3 São } \\
\text { Leo- } \\
\text { poldo }\end{array}$ & $\begin{array}{c}\text { Polo 4 } \\
\text { Sapi- } \\
\text { ranga }\end{array}$ & $\begin{array}{c}\text { Polo } \\
\text { Crés } \\
\text { Cacho- } \\
\text { eiras }\end{array}$ & $\begin{array}{c}\text { Média } \\
\text { Total }\end{array}$ \\
\cline { 2 - 7 } & Média & Média & Média & Média & Média & Média \\
\hline Professores & 4,54 & $4,82^{*}$ & 4,39 & 4,49 & 4,21 & 4,50 \\
\hline Tutores Presenciais & 4,38 & $4,75^{*}$ & 4,21 & 4,28 & 3,93 & 4,32 \\
\hline Tutores a Distância & 4,46 & $4,87^{*}$ & 4,32 & 4,60 & 4,43 & 4,55 \\
\hline Coordenação de Curso e Polo & $4,70^{*}$ & 4,67 & 4,43 & 4,14 & 4,54 & 4,51 \\
\hline Sistema de Ensino & 4,42 & $4,85^{*}$ & 4,32 & 4,67 & 4,48 & 4,54 \\
\hline $\begin{array}{c}\text { Participação em Atividades } \\
\text { Acadêmicas }\end{array}$ & 4,20 & $4,68^{*}$ & 4,00 & 4,23 & 3,91 & 4,22 \\
\hline Organização do Curso & 4,63 & $4,93^{*}$ & 4,31 & 4,77 & 4,46 & 4,65 \\
\hline
\end{tabular}

(Continua) 


\begin{tabular}{c|c|c|c|c|c|c}
\hline $\begin{array}{c}\text { Expectativas referentes a } \\
\text { Conhecimento e Empregabi- } \\
\text { lidade }\end{array}$ & 4,71 & 4,92 & 4,69 & $4,92^{*}$ & 4,66 & 4,78 \\
\hline Condições do Polo & 4,09 & 4,04 & 4,43 & $4,45^{\star}$ & 4,37 & 4,26 \\
\hline Suporte Acadêmico/Técnico & 4,32 & $4,41^{*}$ & 4,20 & 4,40 & 4,07 & 4,29 \\
\hline $\begin{array}{c}\text { Tecnologias de Informação e } \\
\text { Comunicação (TIC's) }\end{array}$ & 4,43 & $4,89^{\star}$ & 4,37 & 4,65 & 4,38 & 4,55 \\
\hline
\end{tabular}

*Maiores médias

Fonte: os autores (2014).

Salienta-se que o Polo de Sapiranga possui convênio com a Universidade Aberta do Brasil (UAB), e os outros são polos PROLIC, ou seja, existe um convênio da UFRGS com a prefeitura da cidade onde o polo está inserido. Pelas informações prestadas pelo Curso, o Polo de Sapiranga apresenta uma infraestrutura melhor que os outros Polos, pois recebem da CAPES/MEC computadores e material para videoconferências, além de o coordenador do polo receber uma bolsa mensal de $\mathrm{R} \$ 1.100,00$ (hum mil e cem reais); ainda, a UAB faz visitas aos polos para avaliálos anualmente. Nos polos PROLIC, os coordenadores de polos não recebem bolsa e a visita é feita pela SEAD/ UFRGS. Há incentivo da parte da SEAD aos polos PROLIC que solicitem à CAPES/ MEC a transformação para polos UAB, e cabe a cada município encaminhar a proposta. O Apêndice B apresenta, por polo, as médias gerais de cada constructo.

Foi aplicado o teste não-paramétrico Kruskal Wallis, a fim de testar a existência de diferenças entre os polos em cada constructo analisado. Este tipo de teste não exige que suposições, tais como normalidade dos dados e homogeneidade de variâncias, sejam satisfeitas para a validação dos resultados.

Somente dois constructos não apresentaram diferença significativa entre as médias dos polos pesquisados: Suporte Acadêmico/Técnico $(\mathrm{p}$-valor $=0,077)$, e Condições do polo $(\mathrm{p}$-valor $=0,671)$. Nos demais constructos que apresentaram diferença significativa, adotou-se o teste de Dunn para as comparações múltiplas.

Para os constructos Tutores Presenciais e Professores, é possível destacar que a maior média encontrada em cada constructo (4,746 e 4,816, respectivamente) é a do Polo de Gravataí, e a menor média (3,934 e 4,208, respectivamente), a 
do Polo de Três Cachoeiras. Para estes dois constructos, a média encontrada em Gravataí é significativamente maior que a de Três Cachoeiras, além de no constructo Professores, Gravataí também possui média significativamente maior que Sapiranga e São Leopoldo. Para os constructos Participação em Atividades Acadêmicas e Expectativas referentes a Conhecimento e Empregabilidade, é possível destacar que a maior média encontrada em ambos constructos (4,675 e 4,922, respectivamente) é a do Polo de Gravataí, sendo que esta difere, significativamente, das menores médias encontradas do Polo de São Leopoldo e Três Cachoeiras, nos dois constructos. O Polo de Sapiranga também apresenta média significativamente maior que o Polo de Três Cachoeiras referente ao constructo Expectativas referentes a Conhecimento e Empregabilidade, conforme a Tabela 5.

Tabela 5 - Teste de Dunn para comparações múltiplas

\begin{tabular}{|c|c|c|c|c|c|c|c|c|c|c|c|c|c|c|c|}
\hline \multirow{3}{*}{$\begin{array}{c}\text { Polo } \\
\text { Gravataí }\end{array}$} & \multicolumn{4}{|c|}{$\begin{array}{c}\text { Tutores } \\
\text { Presenciais }\end{array}$} & \multicolumn{4}{|c|}{ Professores } & \multicolumn{3}{|c|}{$\begin{array}{l}\text { Participação } \\
\text { em Atividades } \\
\text { Acadêmicas }\end{array}$} & \multicolumn{4}{|c|}{$\begin{array}{l}\text { Expectativas referen- } \\
\text { tes a Conhecimento } \\
\text { e Empregabilidade }\end{array}$} \\
\hline & \multicolumn{4}{|c|}{ Média } & \multicolumn{4}{|c|}{ Média } & \multicolumn{3}{|c|}{ Média } & \multicolumn{4}{|c|}{ Média } \\
\hline & 4,746 & A & & & 4,816 & A & & & 4,675 & A & & 4,922 & A & & \\
\hline Alvorada & 4,384 & A & B & & 4,540 & A & B & & 4,233 & A & B & 4,917 & A & B & \\
\hline Sapiranga & 4,278 & A & B & C & 4,488 & & B & C & 4,205 & A & B & 4,712 & A & B & C \\
\hline São Leopoldo & 4,214 & & B & C & 4,392 & & B & C & 4,000 & & B & 4,690 & & B & C \\
\hline $\begin{array}{l}\text { Três Cacho- } \\
\text { eiras }\end{array}$ & 3,934 & & & C & 4,208 & & & C & 3,906 & & B & 4,656 & & & C \\
\hline
\end{tabular}

* Médias seguidas de mesma letra não diferem entre si a 5\% de significância.

Fonte: os autores (2014).

Para o constructo Coordenação de Curso e Polo, conforme evidenciado na Tabela 6, é possível destacar que a maior média encontrada $(4,697)$ é a do Polo de Alvorada, e esta difere significativamente da menor média encontrada $(4,139)$, do Polo de Sapiranga. 
Tabela 6 - Teste de Dunn para comparaç̃̃es múltiplas

\begin{tabular}{c|c|c|c}
\hline & \multicolumn{3}{|c}{ Coordenação de Curso e de Polo } \\
\hline Polo & \multicolumn{3}{|c}{ Média } \\
\hline Alvorada & 4,697 & A & A \\
\hline Gravataí & 4,667 & B & B \\
\hline Três Cachoeiras & 4,542 & A & B \\
\hline São Leopoldo & 4,429 & & \\
\hline Sapiranga & 4,139 & &
\end{tabular}

*Médias seguidas de mesma letra não diferem entre si a 5\% de significância

Fonte: os autores (2014).

Para os constructos Tutores a Distância, Organização do Curso e Tecnologias de Informação e Comunicação, através da Tabela 7, é possível destacar que a maior média encontrada em cada constructo $(4,872,4,930$ e 4,891, respectivamente) é a do Polo de Gravataí, e esta é significativamente maior, para os três constructos, que as médias dos Polos de Três Cachoeiras e São Leopoldo. O Polo de Sapiranga também apresenta média significativamente maior que a do Polo de São Leopoldo no constructo Organização do Curso. O constructo Sistema de Ensino também apresenta maior média no Polo de Gravataí $(4,853)$, sendo que esta é significativamente diferente da menor média encontrada, do Polo de São Leopoldo $(4,320)$.

Tabela 7 - Teste de Dunn para comparações múltiplas

\begin{tabular}{c|c|c|c|c|c|c|c|c|c|c|c|c|c|c}
\hline & \multicolumn{2}{|c|}{$\begin{array}{c}\text { Tutores a Dis- } \\
\text { tância }\end{array}$} & \multicolumn{3}{c|}{$\begin{array}{c}\text { Organização do } \\
\text { Curso }\end{array}$} & \multicolumn{2}{c|}{$\begin{array}{c}\text { Tecnologias de } \\
\text { Informação e } \\
\text { Comunicação }\end{array}$} & \multicolumn{2}{c|}{$\begin{array}{c}\text { Sistema de } \\
\text { Ensino }\end{array}$} \\
\hline Polo & \multicolumn{2}{|c|}{ Média } & \multicolumn{3}{c|}{ Média } & \multicolumn{3}{c}{ Média } & \multicolumn{3}{c}{ Média } \\
\hline Gravataí & 4,872 & A & & 4,930 & A & & & 4,891 & A & & 4,853 & A & \\
\hline Sapiranga & 4,602 & A & B & 4,771 & A & B & & 4,653 & A & B & 4,667 & A & B \\
\hline Alvorada & 4,460 & A & B & 4,631 & A & B & C & 4,426 & A & B & 4,478 & A & B \\
\hline Três Cachoeiras & 4,431 & & B & 4,461 & & B & C & 4,383 & & B & 4,419 & A & B \\
\hline São Leopoldo & 4,323 & & B & 4,310 & & & C & 4,369 & & B & 4,320 & & B \\
\hline
\end{tabular}

*Médias seguidas de mesma letra não diferem entre si a 5\% de significância Fonte: os autores (2014). 


\subsection{Influência dos Construtos na Avaliação do Curso}

A fim de verificar a existência de relação entre os constructos, calculou-se o Coeficiente de Correlação de Pearson, cujos resultados são apresentados na Tabela 12. De acordo com Pestana e Gageiro (2003, p. 189), o “coeficiente de correlação $R$ de Pearson é uma medida de associação linear entre variáveis quantitativas e varia entre -1 e 1". A existência da correlação indica que a intensidade de um fenômeno é acompanhada tendencialmente por outro, embora eles não sejam indissoluvelmente ligados. Por convenção, os autores sugerem que $R<0,2=$ associação muito baixa; $R$ entre 0,2 e $0,39=$ associação baixa; $R$ entre 0,4 e 0,69 $=$ associação moderada; $R$ entre 0,7 e $0,89=$ associação alta; e $R$ entre 0,9 e $1=$ associação muito alta (PESTANA; GAGEIRO, 2003).

De modo geral, os dados demonstram uma alta correlação do constructo Expectativas referentes ao Conhecimento e Empregabilidade com o constructo Organização do Curso $(R=0,846)$ e, da mesma forma, com o Sistema de Ensino $(R=0,808)$, indicando que quanto melhor a percepção de um, é também melhor a percepção do outro.

O constructo Organização do Curso obteve a terceira e quarta maior correlação positiva encontrada com a dimensão Sistema de Ensino $(R=0,807)$ e a dimensão Professores $(R=0,787)$.

A correlação mais baixa encontrada foi entre o constructo Coordenação de Curso e de Polo com as Condições do Polo $(\mathrm{R}=0,377)$, indicando que, não necessariamente, quanto melhor a percepção das Condições do Polo, melhor será a percepção da Coordenação, e vice-versa.

Tabela 8 - Matriz de correlação entre os constructos

\begin{tabular}{|c|c|c|c|c|c|c|c|c|c|c|}
\hline Constructo & 2 & 3 & 4 & 5 & 6 & 7 & 8 & 9 & 10 & 11 \\
\hline 1 &, $707^{\star *}$ &, $771^{\star *}$ &, $708^{* *}$ &, $751^{\star *}$ &, $636^{\star *}$ &, $787^{\star \star *}$ &, $737^{\star \star *}$ &, $421^{\star \star}$ &, $664^{* *}$ &, $676^{* *}$ \\
\hline 2 & &, $687^{\star *}$ &, $535^{\star \star}$ &, $533^{* *}$ &, $461^{\star *}$ &, $610^{* *}$ &, $531^{\star *}$ & $455^{* *}$ &, $616^{\star *}$ &, $532^{* *}$ \\
\hline 3 & & &, $628^{* \star}$ &, $736^{\star *}$ &, $601^{\star \star}$ &, $722^{\star *}$ &, $667^{\star *}$ &, $441^{* *}$ &, $601^{\star *}$ &, $614^{* *}$ \\
\hline 4 & & & &, $644^{\star *}$ &, $479 * *$ &, $626^{\star *}$ &, $577^{\star *}$ & ,377** &, $569^{* *}$ &, $561^{\text {** }}$ \\
\hline 5 & & & & &, $766^{\star *}$ &, $807^{\star \star}$ &, $808^{\star *}$ & $469 * *$ &, $570^{\star *}$ &, $714^{* *}$ \\
\hline 6 & & & & & &, $721^{\star \star}$ &, $672^{\star *}$ &, $442^{* *}$ &, $518^{\star *}$ &, $646^{* *}$ \\
\hline
\end{tabular}

(Continua) 


\begin{tabular}{c|l|l|l|l|l|l|l|l|l|l}
\hline 7 & & & & & & &, $846^{* *}$ &, $474^{* *}$ &, $614^{\star *}$ &, $734^{\star *}$ \\
\hline 8 & & & & & & & &, $416^{\star *}$ &, $523^{\star *}$ &, $671^{\star *}$ \\
\hline 9 & & & & & & & & &, $667^{\star *}$ &, $488^{\star *}$ \\
\hline 10 & & & & & & & & & &, $659^{\star *}$ \\
\hline
\end{tabular}

**Correlação é significativa ao nível de 0,01.

Legenda: (1) Professores, (2) Tutores Presenciais, (3) Tutores a Distância, (4) Coordenação de Curso e Polo, (5) Sistema de Ensino, (6) Participação em Atividades Acadêmicas, (7) Organização do Curso, (8) Expectativas referentes a Conhecimento e Empregabilidade, (9) Condições do Polo, (10) Suporte Acadêmico/Técnico e (11) Tecnologias de Informação e Comunicação (TIC's).

Fonte: os autores (2014).

\section{Considerações Finais}

Foi desenvolvido um instrumento para a avaliação de cursos a distância. Os resultados apurados através da aplicação junto a cinco polos do curso de Licenciatura em Pedagogia, modalidade a distância, na Universidade Federal do Rio Grande do Sul permitiram validar o instrumento proposto. As dimensões pessoas, organização didático-pedagógica e instalações físicas, e os constructos inerentes a cada dimensão permitiram apurar o grau de concordância e/ou discordância dos alunos em relação aos mesmos.

Quanto à dimensão pessoas, verificou-se que as médias atribuídas para todos os constructos foram superiores a 4 (considerando a escala 1 a 5), o que indica que os alunos estão satisfeitos com esta dimensão como um todo. Ressalta-se que o constructo referente aos tutores presenciais recebeu a pior avaliação dos alunos $(4,32)$. Em particular, o item referente ao domínio prático sobre o conteúdo, relacionando-o com a realidade, foi aquele que recebeu pontuação menor $(4,11)$.

Os constructos que compõem a dimensão Organização Didático-Pedagógica, também apresentaram médias superiores a 4 . No entanto, destaca-se a participação em atividades acadêmicas $(4,22)$, e nela, a ampla possibilidade de integração com os colegas em atividades sociais $(4,05)$ como itens que merecem observação.

Por fim, a dimensão referente às Instalações Físicas, que também apresentou média superior a 4 , foi aquela que recebeu pontuações menores. O constructo que apresentou menor média $(4,26)$ foi as Condições do Polo, onde o item referente às necessidades atendidas pelo acervo disponível foi o único que apresentou média inferior a $4(3,82)$. 
Destaca-se, ainda, que os alunos pertencentes ao polo de Gravataí estão, significativamente, mais satisfeitos do que os alunos pertencentes ao polo de São Leopoldo, quanto aos constructos Professores, Tutores a Distância, Sistema de Ensino, Participação em Atividades Acadêmicas, Organização do Curso, Expectativas referentes a Conhecimento e Empregabilidade e TIC. O polo de Gravataí também obteve média significativamente maior que o polo de Três Cachoeiras nos constructos Tutores Presenciais, Professores, Tutores a Distância, Participação em Atividades Acadêmicas, Organização do Curso, Expectativas referentes a Conhecimento e Empregabilidade e TIC.

De modo geral, é possível concluir que, no entender dos alunos, a dimensão Instalações e, nela, a questão específica das condições dos polos é o item que merece atenção especial por parte da coordenação do curso, tendo em vista a realidade diferenciada de cada polo em que o curso é ministrado. Neste sentido, cabe verificar qual a estrutura de funcionamento recomendada pelo Ministério da Educação - INEP/ MEC e, também, pela CAPES, órgão que, atualmente, é responsável pela avaliação dos polos de ensino a distância. É necessário que os cursos estejam atentos aos padrões de qualidade, e que incorporem esses padrões nos seus projetos pedagógicos a fim de criar uma base sólida de funcionamento que garanta a excelência no processo ensino-aprendizagem.

Neste contexto, o instrumento, ora proposto, vem auxiliar as instituições no sentido de apresentar uma ferramenta útil que permite a avaliação das condições de oferta dos cursos ministrados a distância, apresentando coerência interna e adequação às recomendações do Ministério da Educação. O embasamento do referencial teórico e a aplicação prática permitiram concluir que o instrumento proposto é abrangente e possui potencial para ser amplamente utilizado para avaliação da educação a distância em Instituições de Ensino Superior, de natureza pública e/ou privada.

\section{Referências}

ARETIO, L. G. Un concepto integrador de enseñanza a distancia. Radio y educación de adultos, n. 17, 3-6 p., boletín cuatrimestral (quadrimestral) maio/ago., 1991.

FALLER, L. P. Estudo de parâmetros para a avaliação de cursos de ensino a distância (EAD). 2009. 165 f. Dissertação (Mestrado)-Programa de Pós-Graduação em Administração, Universidade Federal de Santa Maria, Santa Maria, 2009. 
FALLER, L. P., RODRIGUES, C. M. C. Proposta de Instrumento para Avaliação de Cursos de Ensino a Distância (EAD). In: ENCONTRO NACIONAL DE ENGENHARIA DE PRODUÇÃO, 3., 2010, São Carlos. Anais... São Carlos, SP: ABREPO, 2010.

HAIR JUNIOR, J. et al. Análise multivariada de dados. 5. ed. Porto Alegre: Bookman, 2005.

LEITE, D. Reformas universitárias: avaliação institucional participativa. Petrópolis, RJ: Vozes, 2005.

LEITE, D. et al. Avaliação participativa online e off-line. Avaliação: RAIES: UNISO, Sorocaba, SP, v. 12, n. 3, p. 445-460, set., 2007.

MINISTÉRIO DA EDUCAÇÃO. Censo da educação superior 2009. Brasília, DF: MEC, 2009. Disponível em: <http://www.inep.mec.gov.br>. Acesso em: 23 maio 2014.

PESTANA, M. H.; GAGEIRO, J. N. Análise de dados para ciências sociais: a complementaridade do SPSS. 3. ed. Lisboa: Sílabo, 2003.

RODRIGUES, A. F. C., OLIVEIRA, J. H. R., RODRIGUES, C. M. C. Indicadores de desempenho para cursos de pós-graduação lato sensu modalidade a distância. In: ENCONTRO NACIONAL DE ENGENHARIA DE PRODUÇÃO, 29., 2009, Salvador. Anais... Salvador, BA: ABREPO, 2009.

UNIVERSIDADE FEDERAL DO RIO GRANDE DO SUL. Relatório de Auto-avaliação Institucional 2009. Porto Alegre: UFRGS; Comissão Própria de Avaliação, 2009.

YIN, R. K. Estudo de caso: planejamento e métodos. 3. ed. Porto Alegre: Bookman, 2005. 


\section{A proposal of evaluation tool for Distance Learning Education \\ Abstract}

This paper proposes an evaluation tool for distance learning education and reports its application at the Federal University of Rio Grande do Sul, Brazil. The proposal is based on bibliographic research. Later, a field study in a Pedagogy distance learning education course was conducted in order to test and validate the tool. The evaluation tool consists of 67 items and includes the following dimensions: (i) faculty, tutors and managing staff; (ii) didactic and pedagogic organization; and (iii) physical facilities. Overall Cronbach's alpha for the questionnaire was 0.982, indicating high internal consistency. A total of 165 students took part in the study. Given the instrument generality, it can be used to evaluate distance learning education initiatives offered by any Higher Education Institution, either public or private.

Keywords: Higher Education. Distance Education. Evaluation Tool.

\section{Propuesta de Instrumento para Evaluación de la Educación a Distancia}

\section{Resumen}

Este artículo propone un instrumento de evaluación para la educación a distancia y relata su aplicación en la Universidad Federal de Rio Grande do Sul, Brasil. Para el desarrollo de la propuesta, se realizó una revisión bibliográfica y una investigación de campo que tratan de verificar el pre-instrumento de evaluación. Esto involucró la participación de los alumnos del Curso de Pedagogía a distancia y la validación se hizo con esta muestra. El instrumento propuesto se compone de 67 items que permiten evaluar las siguientes dimensiones: $I^{\circ}$ ) cuerpo docente, cuerpo de tutores y coordinación, $2^{\circ}$ ) organización didácticopedagógica y $3^{\circ}$ ) instalaciones físicas. El alfa de Cronbach del instrumento fue de 0,982, lo que indica alta consistencia interna y permite la validación del instrumento. En total, 165 estudiantes participaron de la investigación. Debido a la generalidad del instrumento propuesto, se concluye que puede aplicarse para evaluación a distancia ofrecida por cualquier tipo de institución, sea de naturaleza pública o privada.

Palabras clave: Educación superior. Educación a Distancia. Instrumento de Evaluación. 


\section{APÊNDICE A \\ 1 - DADOS DE IDENTIFICAÇÃO}

1.1 Qual seu Curso?

1.2 Qual polo você pertence:

1.3 Qual a distância da sua casa até o polo?

1.4 Ano de Ingresso no Curso:

1.5 Idade: anos

1.6 Sexo: ( ) Feminino ( ) Masculino

\subsection{Estado Civil:}

( ) Casado(a) ( ) Solteiro(a) ( ) Separado(a)/desquitado(a)/divorciado(a)

( ) Viúvo(a) ( ) Outro

1.8 Quantos filhos você tem?

( ) Nenhum.

( ) Um.

( ) Dois.

( ) Três.

( ) Quatro ou mais.

1.9 Em que você trabalha atualmente? (Marque apenas uma resposta)

( ) Na agricultura, no campo, na fazenda ou na pesca.

( ) Na indústria.

( ) Na construção civil.

( ) No comércio, banco, transporte, hotelaria ou outros serviços.

( ) Como funcionário(a) do Governo Federal, Estadual ou Municipal.

( ) Como profissional liberal, professor(a) ou técnico(a) de nível superior.

( ) Outro.

( ) Não trabalho.

1.10 Faixa mensal de renda familiar: 
( ) De R $\$ 0$ a R $\$ 1.020,00$ (até 2 S.M).

( ) De R\$1.020,00 a R \$2.040,00 (entre 2 e 4 S.M).

( ) De R $\$ 2.040,00$ a R\$5.100,00 (entre 4 e 10 S.M).

( ) De R\$5.100,00 a R\$10.200,00(entre 10 e 20 S.M).

( ) Acima de R $\$ 10.200,00$ (acima de 20 S.M).

1.11 Quantas horas semanais você trabalha?

( ) Sem jornada fixa, até 10 horas semanais.

( ) De 11 a 20 horas semanais.

( ) De 21 a 30 horas semanais.

( ) De 31 a 40 horas semanais.

( ) Mais de 40 horas semanais.

1.12 Quantas horas semanais você dedica aos estudos?

( ) Sem jornada fixa, até 10 horas semanais.

( ) De 11 a 20 horas semanais.

( ) De 21 a 30 horas semanais.

( ) De 31 a 40 horas semanais.

( ) Mais de 40 horas semanais.

1.13 Qual o seu domínio do uso de informática antes de ingressar no curso:
( ) Ótimo
( ) Bom
( ) Regular
( ) Ruim
( ) Péssimo

1.14 Você possui computador em casa?
( ) Sim
( ) Não

1.15 Seu computador possui acesso à internet?
( ) Sim
( ) Não

INSTRUÇÕES DE PREENCHIMENTO:

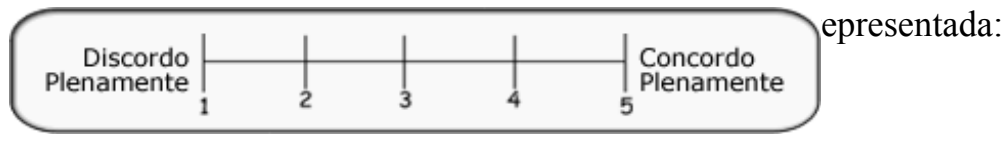




\section{2 - CORPO DOCENTE, CORPO DE TUTORES E COORDENAÇÃO}

\section{1 - Os professores...}

\begin{tabular}{|l|l|l|l|l|l|l|l|}
\hline No & Questão & \multicolumn{5}{|c|}{$\begin{array}{l}\text { Discordo } \\
\text { plenamente }\end{array}$} & \multicolumn{5}{|c|}{$\begin{array}{l}\text { Concordo Não se } \\
\text { plenamente aplica }\end{array}$} \\
\hline 01 & $\begin{array}{l}\text { demonstram domínio teórico sobre o conte- } \\
\text { údo. }\end{array}$ & 1 & 2 & 3 & 4 & 5 & \\
\hline 02 & $\begin{array}{l}\text { demonstram domínio prático sobre o conteú- } \\
\text { do, relacionando-o com a realidade. }\end{array}$ & 1 & 2 & 3 & 4 & 5 & \\
\hline 03 & esclarecem minhas dúvidas. & 1 & 2 & 3 & 4 & 5 & \\
\hline 04 & interagem com os alunos. & 1 & 2 & 3 & 4 & 5 & \\
\hline 05 & demonstram interesse no meu aprendizado. & 1 & 2 & 3 & 4 & 5 & \\
\hline 06 & $\begin{array}{l}\text { fornecem retorno das atividades realizadas } \\
\text { nos prazos previstos. }\end{array}$ & 1 & 2 & 3 & 4 & 5 & \\
\hline 07 & $\begin{array}{l}\text { demonstram domínio das tecnologias de in- } \\
\text { formação e comunicação utilizadas no curso. }\end{array}$ & 1 & 2 & 3 & 4 & 5 & \\
\hline 08 & são assíduos e pontuais. & 1 & 2 & 3 & 4 & 5 & \\
\hline 09 & estimulam o relacionamento interpessoal. & 1 & 2 & 3 & 4 & 5 & \\
\hline
\end{tabular}

\section{2 - Os Tutores Presenciais...}

\begin{tabular}{|c|c|c|c|c|c|c|c|}
\hline \multirow{2}{*}{$\begin{array}{l}N^{\circ} \\
10\end{array}$} & \multirow{2}{*}{$\begin{array}{l}\text { Questão } \\
\text { demonstram domínio teórico sobre o con- } \\
\text { teúdo. }\end{array}$} & \multicolumn{3}{|c|}{$\begin{array}{l}\text { Discordo } \\
\text { plenamente }\end{array}$} & \multicolumn{2}{|c|}{$\begin{array}{l}\text { Concordo } \\
\text { plenamente }\end{array}$} & \multirow{2}{*}{$\begin{array}{l}\text { Não } \\
\text { se } \\
\text { aplica }\end{array}$} \\
\hline & & 1 & 2 & 3 & 4 & 5 & \\
\hline 11 & $\begin{array}{l}\text { demonstram domínio prático sobre o conte- } \\
\text { údo, relacionando-o com a realidade. }\end{array}$ & 1 & 2 & 3 & 4 & 5 & \\
\hline 12 & esclarecem minhas dúvidas. & 1 & 2 & 3 & 4 & 5 & \\
\hline 13 & interagem com os alunos. & 1 & 2 & 3 & 4 & 5 & \\
\hline 14 & $\begin{array}{l}\text { demonstram interesse pelo meu aprendi- } \\
\text { zado. }\end{array}$ & 1 & 2 & 3 & 4 & 5 & \\
\hline 15 & $\begin{array}{l}\text { demonstram domínio das tecnologias de in- } \\
\text { formação e comunicação utilizadas no curso. }\end{array}$ & 1 & 2 & 3 & 4 & 5 & \\
\hline 16 & são assíduos e pontuais. & 1 & 2 & 3 & 4 & 5 & \\
\hline 17 & estimulam o relacionamento interpessoal. & 1 & 2 & 3 & 4 & 5 & \\
\hline
\end{tabular}




\section{3 - Os Tutores a Distância...}

\begin{tabular}{|c|c|c|c|c|c|c|c|}
\hline \multirow{2}{*}{$\begin{array}{l}\mathrm{N}^{\circ} \\
18\end{array}$} & \multirow{2}{*}{$\begin{array}{l}\text { Questão } \\
\text { demonstram domínio teórico sobre o con- } \\
\text { teúdo. }\end{array}$} & \multicolumn{3}{|c|}{$\begin{array}{l}\text { Discordo } \\
\text { plenamente }\end{array}$} & \multicolumn{2}{|c|}{$\begin{array}{r}\text { Concordo } \\
\text { plenamente }\end{array}$} & \multirow[t]{2}{*}{$\begin{array}{l}\text { Não } \\
\text { se } \\
\text { aplica }\end{array}$} \\
\hline & & 1 & 2 & 3 & 4 & 5 & \\
\hline 19 & $\begin{array}{l}\text { demonstram domínio prático sobre o conte- } \\
\text { údo, relacionando-o com a realidade. }\end{array}$ & 1 & 2 & 3 & 4 & 5 & \\
\hline 20 & esclarecem minhas dúvidas. & 1 & 2 & 3 & 4 & 5 & \\
\hline 21 & interagem com os alunos. & 1 & 2 & 3 & 4 & 5 & \\
\hline 22 & $\begin{array}{l}\text { demonstram interesse pelo meu aprendi- } \\
\text { zado. }\end{array}$ & 1 & 2 & 3 & 4 & 5 & \\
\hline 23 & $\begin{array}{l}\text { fornecem retorno das atividades realizadas } \\
\text { nos prazos previstos. }\end{array}$ & 1 & 2 & 3 & 4 & 5 & \\
\hline 24 & $\begin{array}{l}\text { demonstram domínio das tecnologias de in- } \\
\text { formação e comunicação utilizadas no curso. }\end{array}$ & 1 & 2 & 3 & 4 & 5 & \\
\hline 25 & são assíduos e pontuais. & 1 & 2 & 3 & 4 & 5 & \\
\hline 26 & estimulam o relacionamento interpessoal. & 1 & 2 & 3 & 4 & 5 & \\
\hline
\end{tabular}

\section{4 - Coordenação de Curso e de Polo}

\begin{tabular}{|c|c|c|c|c|c|c|c|}
\hline \multirow{2}{*}{$\begin{array}{l}N^{\circ} \\
27 \\
27\end{array}$} & \multirow{2}{*}{$\begin{array}{l}\text { Questão } \\
\text { A coordenação administrativa do Polo } \\
\text { gerencia de modo adequado as diversas } \\
\text { demandas dos alunos e do curso. }\end{array}$} & \multicolumn{3}{|c|}{$\begin{array}{l}\text { Discordo } \\
\text { plenamente }\end{array}$} & \multicolumn{2}{|c|}{$\begin{array}{l}\text { Concordo } \\
\text { plenamente }\end{array}$} & \multirow[t]{2}{*}{$\begin{array}{l}\text { Não } \\
\text { se } \\
\text { aplica }\end{array}$} \\
\hline & & 1 & 2 & 3 & 4 & 5 & \\
\hline 28 & $\begin{array}{l}\text { A coordenação pedagógica do Polo } \\
\text { gerencia de modo adequado as diversas } \\
\text { demandas dos alunos e do curso. }\end{array}$ & 1 & 2 & 3 & 4 & 5 & \\
\hline 29 & $\begin{array}{l}\text { A coordenação do curso gerencia de modo } \\
\text { adequado as diversas demandas dos alu- } \\
\text { nos e do curso. }\end{array}$ & 1 & 2 & 3 & 4 & 5 & \\
\hline
\end{tabular}




\section{3 - ORGANIZAÇÃO DIDÁTICO-PEDAGÓGICA}

\section{1 - Sistema de Ensino}

\begin{tabular}{|c|c|c|c|c|c|c|c|}
\hline \multirow{2}{*}{$\begin{array}{l}N^{\circ} \\
30 \\
30\end{array}$} & \multirow{2}{*}{$\begin{array}{l}\text { Questão } \\
\text { A estrutura curricular do curso é adequa- } \\
\text { da aquilo que é requerido pelo mercado } \\
\text { de trabalho. }\end{array}$} & \multicolumn{3}{|c|}{$\begin{array}{l}\text { Discordo } \\
\text { plenamente }\end{array}$} & \multicolumn{2}{|c|}{$\begin{array}{r}\text { Concordo } \\
\text { plenamente }\end{array}$} & \multirow[t]{2}{*}{$\begin{array}{l}\text { Não se } \\
\text { aplica }\end{array}$} \\
\hline & & 1 & 2 & 3 & 4 & 5 & \\
\hline 31 & $\begin{array}{l}\text { As cargas horárias das disciplinas são } \\
\text { bem dimensionadas. }\end{array}$ & 1 & 2 & 3 & 4 & 5 & \\
\hline 32 & $\begin{array}{l}\text { A integração das disciplinas é organizada } \\
\text { de modo adequado. }\end{array}$ & 1 & 2 & 3 & 4 & 5 & \\
\hline 33 & $\begin{array}{l}\text { O foco do curso se dá mais no desenvolvi- } \\
\text { mento de competências e habilidades do } \\
\text { que no controle ( }{ }^{\circ} \text { de acesso ao ambien- } \\
\text { te, datas de entregas de trabalhos, etc.). }\end{array}$ & 1 & 2 & 3 & 4 & 5 & \\
\hline 34 & $\begin{array}{l}\text { A avaliação da aprendizagem através de } \\
\text { provas, acessos aos ambientes de aprendi- } \\
\text { zagem, etc. é desenvolvida de forma apro- } \\
\text { priada e promove o feedback contínuo. }\end{array}$ & 1 & 2 & 3 & 4 & 5 & \\
\hline 35 & $\begin{array}{l}\text { As metodologias e dinâmicas de ensino } \\
\text { são adequadas. }\end{array}$ & 1 & 2 & 3 & 4 & 5 & \\
\hline
\end{tabular}

\section{2 - Participação em Atividades Acadêmicas}

\begin{tabular}{|l|l|l|l|l|l|l|l|}
\hline No & Questão & \multicolumn{3}{|c|}{$\begin{array}{l}\text { Discordo } \\
\text { plenamente }\end{array}$} & $\begin{array}{c}\text { Concordo } \\
\text { plenamente }\end{array}$ & $\begin{array}{l}\text { Não } \\
\text { se } \\
\text { aplica }\end{array}$ \\
\hline 36 & $\begin{array}{l}\text { Existe ampla possibilidade de interação } \\
\text { com os colegas em atividades acadêmicas. }\end{array}$ & 1 & 2 & 3 & 4 & 5 & \\
\hline 37 & $\begin{array}{l}\text { Existe ampla possibilidade de interação } \\
\text { com os colegas em atividades sociais. }\end{array}$ & 1 & 2 & 3 & 4 & 5 & \\
\hline 38 & $\begin{array}{l}\text { O tempo demandado pelo curso em estu- } \\
\text { dos e trabalhos individuais é adequado. }\end{array}$ & 1 & 2 & 3 & 4 & 5 & \\
\hline 39 & $\begin{array}{l}\text { O tempo demandado pelo curso em estu- } \\
\text { dos e trabalhos em grupo é adequado. }\end{array}$ & 1 & 2 & 3 & 4 & 5 & \\
\hline 40 & $\begin{array}{l}\text { As participações presenciais exigidas são } \\
\text { adequadas. }\end{array}$ & 1 & 2 & 3 & 4 & 5 & \\
\hline
\end{tabular}




\section{3 - Organização do Curso}

\begin{tabular}{|c|c|c|c|c|c|c|c|}
\hline \multirow{2}{*}{$\begin{array}{l}\mathrm{N}^{\circ} \\
41\end{array}$} & \multirow{2}{*}{$\begin{array}{l}\text { Questão } \\
\text { O Curso dá abertura para sugestões e } \\
\text { opiniões sobre o trabalho que está sendo } \\
\text { desenvolvido. }\end{array}$} & \multicolumn{3}{|c|}{$\begin{array}{l}\text { Discordo } \\
\text { plenamente }\end{array}$} & \multicolumn{2}{|c|}{$\begin{array}{r}\text { Concordo } \\
\text { plenamente }\end{array}$} & \multirow[t]{2}{*}{$\begin{array}{l}\text { Não } \\
\text { se } \\
\text { aplica }\end{array}$} \\
\hline & & 1 & 2 & 3 & 4 & 5 & \\
\hline 42 & $\begin{array}{l}\text { Existe um clima de relacionamento } \\
\text { amistoso entre professores, tutores e } \\
\text { coordenadores. }\end{array}$ & 1 & 2 & 3 & 4 & 5 & \\
\hline 43 & $\begin{array}{l}\text { Existe respeito às regras, normas e com- } \\
\text { promissos estabelecidos pelo Curso. }\end{array}$ & 1 & 2 & 3 & 4 & 5 & \\
\hline 44 & $\begin{array}{l}\text { O Curso preocupa-se com a qualidade do } \\
\text { aluno que está saindo para o mercado de } \\
\text { trabalho. }\end{array}$ & 1 & 2 & 3 & 4 & 5 & \\
\hline
\end{tabular}

\section{4 - Expectativas referentes a Conhecimento e Empregabilidade}

\begin{tabular}{|l|l|l|l|l|l|l|l|}
\hline No & Questão & \multicolumn{3}{|l|}{$\begin{array}{l}\text { Discordo } \\
\text { plenamente }\end{array}$} & $\begin{array}{l}\text { Concordo } \\
\text { plenamente }\end{array}$ & $\begin{array}{l}\text { Não } \\
\text { se } \\
\text { aplica }\end{array}$ \\
\hline 45 & $\begin{array}{l}\text { O Curso fornece a possibilidade de expe- } \\
\text { rimentar as práticas de trabalho. }\end{array}$ & 1 & 2 & 3 & 4 & 5 & \\
\hline 46 & $\begin{array}{l}\text { O Curso fornece a possibilidade de arti- } \\
\text { cular os conteúdos de sala de aula com a } \\
\text { realidade. }\end{array}$ & 1 & 2 & 3 & 4 & 5 & \\
\hline 47 & $\begin{array}{l}\text { O Curso fornece a possibilidade de quali- } \\
\text { ficar meu trabalho. }\end{array}$ & 1 & 2 & 3 & 4 & 5 & \\
\hline 48 & $\begin{array}{l}\text { O Curso fornece a possibilidade de me- } \\
\text { Ihorar meu currículo. }\end{array}$ & 1 & 2 & 3 & 4 & 5 & \\
\hline 49 & $\begin{array}{l}\text { O Curso fornece a possibilidade de me- } \\
\text { Ihorar minha empregabilidade. }\end{array}$ & 1 & 2 & 3 & 4 & 5 & \\
\hline 50 & $\begin{array}{l}\text { O Curso fornece a possibilidade de formar } \\
\text { uma rede de relacionamento profissional. }\end{array}$ & 1 & 2 & 3 & 4 & 5 & \\
\hline
\end{tabular}




\section{4 - INSTALAÇÕES FÍSICAS}

\section{1 - Condições do Polo}

\begin{tabular}{|c|c|c|c|c|c|c|c|}
\hline \multirow{2}{*}{\begin{tabular}{|l}
$\mathrm{N}^{\circ}$ \\
51
\end{tabular}} & \multirow{2}{*}{$\begin{array}{l}\text { Questão } \\
\text { O polo é de fácil acesso. }\end{array}$} & \multicolumn{3}{|c|}{$\begin{array}{l}\text { Discordo } \\
\text { plenamente }\end{array}$} & \multicolumn{2}{|c|}{$\begin{array}{r}\text { Concordo } \\
\text { plenamente }\end{array}$} & \multirow[t]{2}{*}{$\begin{array}{l}\text { Não } \\
\text { se } \\
\text { aplica }\end{array}$} \\
\hline & & 1 & 2 & 3 & 4 & 5 & \\
\hline 52 & $\begin{array}{l}\text { Os horários de funcionamento do polo são } \\
\text { adequados. }\end{array}$ & 1 & 2 & 3 & 4 & 5 & \\
\hline 53 & $\begin{array}{l}\text { As salas de aula utilizadas em atividades } \\
\text { presenciais são adequadas. }\end{array}$ & 1 & 2 & 3 & 4 & 5 & \\
\hline 54 & $\begin{array}{l}\text { As instalações, funcionamento e acesso à } \\
\text { biblioteca do polo são adequados. }\end{array}$ & 1 & 2 & 3 & 4 & 5 & \\
\hline 55 & $\begin{array}{l}\text { O acervo disponível na Biblioteca atende às } \\
\text { necessidades do Curso. }\end{array}$ & 1 & 2 & 3 & 4 & 5 & \\
\hline 56 & $\begin{array}{l}\text { As instalações administrativas do polo são } \\
\text { adequadas. }\end{array}$ & 1 & 2 & 3 & 4 & 5 & \\
\hline 57 & $\begin{array}{l}\text { O espaço de convivência do polo é ade- } \\
\text { quado. }\end{array}$ & 1 & 2 & 3 & 4 & 5 & \\
\hline 58 & $\begin{array}{l}\text { Os equipamentos disponíveis nos polos são } \\
\text { adequados. }\end{array}$ & 1 & 2 & 3 & 4 & 5 & \\
\hline 59 & $\begin{array}{l}\text { Os laboratórios especializados no polo para } \\
\text { realização das atividades são adequados. }\end{array}$ & 1 & 2 & 3 & 4 & 5 & \\
\hline
\end{tabular}

\section{2 - Suporte Acadêmico/ Técnico}

\begin{tabular}{|c|c|c|c|c|c|c|c|}
\hline \multirow{2}{*}{$\frac{N^{\circ}}{60}$} & \multirow{2}{*}{$\begin{array}{l}\text { Questão } \\
\text { O suporte online é adequado. }\end{array}$} & \multicolumn{3}{|c|}{$\begin{array}{l}\text { Discordo } \\
\text { plenamente }\end{array}$} & \multicolumn{2}{|c|}{$\begin{array}{l}\text { Concordo } \\
\text { plenamente }\end{array}$} & \multirow[t]{2}{*}{$\begin{array}{l}\text { Não } \\
\text { se } \\
\text { aplica }\end{array}$} \\
\hline & & 1 & 2 & 3 & 4 & 5 & \\
\hline 61 & O suporte presencial é adequado. & 1 & 2 & 3 & 4 & 5 & \\
\hline 62 & $\begin{array}{l}\text { Existem treinamentos para capacitar no uso } \\
\text { dos ambientes de aprendizagem. }\end{array}$ & 1 & 2 & 3 & 4 & 5 & \\
\hline 63 & $\begin{array}{l}\text { A qualidade de acesso à internet do polo é } \\
\text { adequada. }\end{array}$ & 1 & 2 & 3 & 4 & 5 & \\
\hline
\end{tabular}




\section{3 - Tecnologias de Informação e Comunicação (TIC's)}

\begin{tabular}{|c|l|l|l|l|l|l|l|}
\hline No & Questão & \multicolumn{3}{|c|}{$\begin{array}{l}\text { Discordo } \\
\text { plenamente }\end{array}$} \\
64 & $\begin{array}{l}\text { Os materiais didáticos (impressos, audio- } \\
\text { visuais e/ou para internet) são elabo- } \\
\text { rados de forma clara e compreensível, } \\
\text { promovendo a autonomia de estudos. }\end{array}$ & 1 & 2 & 3 & 4 & 5 & $\begin{array}{l}\text { Não } \\
\text { se } \\
\text { aplica }\end{array}$ \\
\hline 65 & $\begin{array}{l}\text { As ferramentas síncronas (chats, internet, } \\
\text { telefone, etc.) disponíveis cumprem com } \\
\text { seus propósitos. }\end{array}$ & 1 & 2 & 3 & 4 & 5 & \\
\hline 66 & $\begin{array}{l}\text { As ferramentas assíncronas (e-mails, } \\
\text { CD's, DVD's, Fax, vídeos, etc.) disponíveis } \\
\text { cumprem com seus propósitos. }\end{array}$ & 1 & 2 & 3 & 4 & 5 & \\
\hline 67 & $\begin{array}{l}\text { Os ambientes de aprendizagem adota- } \\
\text { dos no Curso são de fácil utilização. }\end{array}$ & 1 & 2 & 3 & 4 & 5 & \\
\hline
\end{tabular}

\section{ESPAÇO ABERTO PARA SUGESTÕES}




\section{APÊNDICE B}

\section{MÉDIAS GERAIS, POR POLO, DOS CONSTRUCTOS AVALIADOS}

\begin{tabular}{|c|c|c|c|c|c|c|}
\hline Variáveis & Polo1 & Polo2 & Polo3 & Polo4 & Polo5 & Tota \\
\hline 01 - Domínio teórico (conteúdo). & 4,71 & 5,00 & 4,71 & 4,92 & 4,56 & 4,78 \\
\hline 02 - Domínio prático (conteúdo). & 4,53 & 4,78 & 4,33 & 4,64 & 4,34 & 4,54 \\
\hline 03 - Esclarecimento das dúvidas. & 4,62 & 4,84 & 4,52 & 4,47 & 4,19 & 4,53 \\
\hline 04 - Interação com os alunos. & 4,53 & 4,84 & 4,38 & 4,47 & 4,28 & 4,51 \\
\hline 05 - Interesse no aprendizado. & 4,62 & 4,91 & 4,43 & 4,53 & 4,47 & 4,60 \\
\hline 06 - Feedback nos prazos previstos. & 4,29 & 4,63 & 4,10 & 4,11 & 3,94 & 4,22 \\
\hline 07 - Domínio das TIC's utilizadas. & 4,31 & 4,66 & 4,29 & 4,53 & 4,03 & 4,36 \\
\hline 08 - Assiduidade e pontualidade. & 4,64 & 4,81 & 4,43 & 4,22 & 3,97 & 4,42 \\
\hline $\begin{array}{l}09 \text { - Estímulo ao relacionamento } \\
\text { interpessoal. }\end{array}$ & 4,67 & 4,88 & 4,33 & 4,50 & 4,09 & 4,52 \\
\hline Média 'Professores' & 4,55 & 4,82 & 4,39 & 4,49 & 4,21 & 4,50 \\
\hline 10 - Domínio teórico (conteúdo). & 4,22 & 4,69 & 3,95 & 4,17 & 3,66 & 4,16 \\
\hline 11 - Domínio prático (conteúdo). & 4,16 & 4,63 & 3,95 & 4,11 & 3,66 & 4,11 \\
\hline 12 - Esclarecimento das dúvidas. & 4,29 & 4,69 & 4,24 & 4,31 & 3,84 & 4,27 \\
\hline 13 - Interação com os alunos. & 4,53 & 4,84 & 4,38 & 4,47 & 4,16 & 4,48 \\
\hline 14 - Interesse no aprendizado. & 4,51 & 4,81 & 4,29 & 4,31 & 3,84 & 4,36 \\
\hline 15 - Domínio das TIC's utilizadas. & 4,31 & 4,72 & 4,38 & 4,22 & 4,00 & 4,32 \\
\hline 16 - Assiduidade e pontualidade. & 4,60 & 4,75 & 4,19 & 4,28 & 4,22 & 4,43 \\
\hline $\begin{array}{l}17 \text { - Estímulo ao relacionamento } \\
\text { interpessoal. }\end{array}$ & 4,53 & 4,84 & 4,33 & 4,36 & 4,09 & 4,44 \\
\hline Média 'Tutores Presenciais' & 4,39 & 4,75 & 4,21 & 4,28 & 3,93 & 4,32 \\
\hline 18 - Domínio teórico (conteúdo). & 4,51 & 4,81 & 4,38 & 4,75 & 4,56 & 4,61 \\
\hline 19 - Domínio prático (conteúdo). & 4,47 & 4,72 & 4,14 & 4,64 & 4,41 & 4,50 \\
\hline 20 - Esclarecimento das dúvidas. & 4,47 & 4,88 & 4,43 & 4,64 & 4,53 & 4,59 \\
\hline 21 - Interação com os alunos. & 4,51 & 4,94 & 4,43 & 4,67 & 4,56 & 4,62 \\
\hline 22 - Interesse no aprendizado. & 4,51 & 4,94 & 4,33 & 4,64 & 4,56 & 4,61 \\
\hline 23 - Feedback nos prazos previstos. & 4,33 & 4,81 & 4,24 & 4,33 & 4,16 & 4,38 \\
\hline 24 - Domínio das TIC's utilizadas. & 4,51 & 4,91 & 4,57 & 4,72 & 4,53 & 4,64 \\
\hline 25 - Assiduidade e pontualidade. & 4,47 & 4,91 & 4,19 & 4,47 & 4,16 & 4,45 \\
\hline $\begin{array}{l}26 \text { - Estímulo ao relacionamento } \\
\text { interpessoal. }\end{array}$ & 4,47 & 4,94 & 4,19 & 4,56 & 4,41 & 4,53 \\
\hline
\end{tabular}

(Continua) 


\begin{tabular}{|c|c|c|c|c|c|c|}
\hline Variáveis & Polo1 & Polo2 & Polo3 & Polo4 & Polo5 & Total \\
\hline Média 'Tutores a Distância' & 4,47 & 4,87 & 4,32 & 4,60 & 4,43 & 4,55 \\
\hline 27-Coordenação Administrativa do Polo. & 4,73 & 4,69 & 4,5 & 3,8 & 4,7 & 4,48 \\
\hline 28 -Coordenaação Pedagógica. & 4,71 & 4,69 & 4,4 & 4,1 & 4,5 & 4,49 \\
\hline 29 -Coordenação do Curso. & 4,67 & 4,63 & 4,4 & 4,4 & 4,5 & 4,54 \\
\hline Média 'Coordenação de Curso e Polo' & 4,70 & 4,67 & 4,43 & 4,14 & 4,54 & 4,55 \\
\hline 30 - Estrutura curricular do curso. & 4,64 & 4,91 & 4,43 & 4,83 & 4,50 & 4,68 \\
\hline 31 - Cargas horárias. & 4,47 & 4,75 & 4,24 & 4,53 & 4,63 & 4,53 \\
\hline 32 - Integração das disciplinas. & 4,44 & 4,91 & 4,38 & 4,78 & 4,72 & 4,65 \\
\hline 33 - Desenvolvimento de competências. & 4,00 & 4,78 & 4,10 & 4,31 & 4,19 & 4,27 \\
\hline 34 - Feedback contínuo. & 4,33 & 4,88 & 4,14 & 4,67 & 4,28 & 4,47 \\
\hline 35 - Metodologias adequadas. & 4,49 & 4,84 & 4,33 & 4,81 & 4,53 & 4,61 \\
\hline Média 'Sistema de Ensino' & 4,40 & 4,84 & 4,27 & 4,65 & 4,47 & 4,54 \\
\hline $\begin{array}{l}36 \text {-Integração com colegas em ativ. } \\
\text { acadêmicas. }\end{array}$ & 4,36 & 4,81 & 4,00 & 4,33 & 3,97 & 4,32 \\
\hline $\begin{array}{l}37 \text {-Integração com colegas em ativ. } \\
\text { sociais. }\end{array}$ & 4,11 & 4,75 & 3,81 & 3,92 & 3,56 & 4,05 \\
\hline $\begin{array}{l}38 \text { - Tempo em estudos e trabalhos } \\
\text { individuais. }\end{array}$ & 4,13 & 4,56 & 4,00 & 4,19 & 3,94 & 4,18 \\
\hline $\begin{array}{l}39 \text { - Tempo em estudos e trabalhos } \\
\text { em grupo. }\end{array}$ & 4,13 & 4,59 & 3,71 & 4,08 & 3,84 & 4,10 \\
\hline 40 - Participações presenciais adequadas. & 4,27 & 4,66 & 4,48 & 4,64 & 4,22 & 4,44 \\
\hline $\begin{array}{l}\text { Média 'Participação em Atividades } \\
\text { Acadêmicas' }\end{array}$ & 4,20 & 4,68 & 4,00 & 4,23 & 3,91 & 4,22 \\
\hline 41 - Abertura para sugestões e opiniões. & 4,44 & 4,97 & 4,10 & 4,58 & 4,13 & 4,47 \\
\hline 42 - Relacionamento amistoso. & 4,69 & 4,94 & 4,43 & 4,83 & 4,53 & 4,70 \\
\hline 43 - Respeito às regras e compromissos. & 4,71 & 4,91 & 4,19 & 4,81 & 4,53 & 4,67 \\
\hline $\begin{array}{l}44 \text { - Qualidade do aluno que ingressa } \\
\text { para o mercado de trabalho. }\end{array}$ & 4,71 & 4,91 & 4,52 & 4,86 & 4,66 & 4,75 \\
\hline Média 'Organização do Curso' & 4,64 & 4,93 & 4,31 & 4,77 & 4,46 & 4,65 \\
\hline 45 - Experimentar as práticas de trabalho. & 4,62 & 4,94 & 4,67 & 4,97 & 4,66 & 4,77 \\
\hline 46 -Conteúdos de sala de aula/realidade. & 4,76 & 4,94 & 4,57 & 4,92 & 4,66 & 4,78 \\
\hline 47 - Qualificar o trabalho. & 4,76 & 4,94 & 4,76 & 4,94 & 4,69 & 4,82 \\
\hline 48 - Melhorar o currículo. & 4,76 & 4,91 & 4,81 & 4,94 & 4,78 & 4,84 \\
\hline 49 - Melhorar a empregabilidade. & 4,71 & 4,91 & 4,71 & 4,92 & 4,66 & 4,78 \\
\hline $\begin{array}{l}50 \text { - Formar uma rede de relaciona- } \\
\text { mento pessoal. }\end{array}$ & 4,71 & 4,91 & 4,62 & 4,81 & 4,50 & 4,72 \\
\hline
\end{tabular}




\begin{tabular}{|c|c|c|c|c|c|c|}
\hline Variáveis & Polo1 & Polo2 & Polo3 & Polo4 & Polo5 & Total \\
\hline $\begin{array}{l}\text { Média 'Expect. Ref. a Conhecimento e } \\
\text { Empregabilidade' }\end{array}$ & 4,72 & 4,92 & 4,69 & 4,92 & 4,66 & 4,78 \\
\hline 51 - Polo de fácil acesso. & 3,64 & 4,38 & 4,90 & 4,92 & 4,38 & 4,36 \\
\hline 52 - Horários de funcionamento. & 4,29 & 4,44 & 4,38 & 4,67 & 4,75 & 4,50 \\
\hline 53 - Salas de aula utilizadas. & 3,82 & 3,94 & 4,38 & 4,72 & 4,63 & 4,26 \\
\hline $\begin{array}{l}54 \text { - Instalações, funcionamento e } \\
\text { acesso à bibllioteca. }\end{array}$ & 4,22 & 3,97 & 4,19 & 4,25 & 4,25 & 4,18 \\
\hline 55 - Acervo disponível. & 4,27 & 3,94 & 4,19 & 3,14 & 3,63 & 3,82 \\
\hline 56 - Inst. administrativas adequadas. & 4,09 & 3,94 & 4,57 & 4,69 & 4,41 & 4,31 \\
\hline 57 - Espaço de convivência adequado. & 4,13 & 4,00 & 4,43 & 4,19 & 4,66 & 4,25 \\
\hline 58 - Equipamentos disponíveis. & 4,24 & 3,84 & 4,43 & 4,69 & 4,38 & 4,31 \\
\hline 59 - Laboratórios especializados. & 4,24 & 3,91 & 4,43 & 4,78 & 4,28 & 4,32 \\
\hline Média 'Condições do Polo' & 4,11 & 4,04 & 4,43 & 4,45 & 4,37 & 4,26 \\
\hline 60 - Suporte online adequado. & 4,51 & 4,69 & 4,38 & 4,61 & 4,44 & 4,53 \\
\hline 61 - Suporte presencial adequado. & 4,51 & 4,59 & 4,48 & 4,58 & 4,53 & 4,54 \\
\hline $\begin{array}{l}62 \text { - Treinamentos para ambientes de } \\
\text { aprendizagem. }\end{array}$ & 4,31 & 4,34 & 3,86 & 3,97 & 3,50 & 4,02 \\
\hline 63 - Qualidade do acesso a Internet. & 4,02 & 4,00 & 4,10 & 4,42 & 3,81 & 4,07 \\
\hline Média 'Suporte Acadêmico/Técnico' & 4,34 & 4,41 & 4,20 & 4,40 & 4,07 & 4,29 \\
\hline 64 - Materiais didáticos claros. & 4,42 & 4,88 & 4,52 & 4,72 & 4,50 & 4,60 \\
\hline 65 - Ferramentas síncronas. & 4,44 & 4,97 & 4,33 & 4,61 & 4,22 & 4,52 \\
\hline 66 - Ferramentas assíncronas. & 4,40 & 4,84 & 4,38 & 4,64 & 4,38 & 4,53 \\
\hline 67 - Ambientes de aprendizagem. & 4,49 & 4,88 & 4,24 & 4,64 & 4,44 & 4,55 \\
\hline Média 'TIC' & 4,39 & 4,65 & 4,29 & 4,52 & 4,23 & 4,55 \\
\hline
\end{tabular}

